\title{
Measuring perceived beauty of the Great Barrier Reef using eye- tracking technology
}

Noel Scott, Dung Le, Susanne Beckenand Rod M. Connolly

\section{Abstract}

The purpose of this research is to test the usefulness of eye-tracking in measuring the perceived beauty of photos of the Great Barrier Reef. Eyetracking is used to measure visual attention (fixation count, fixation duration) to 21 photos ranked in the degree of perceived beauty. Results indicate significant differences in visual attention to 'beautiful' and 'ugly' photos and a significant correlation between average perceived beauty and attention measures. This study provides evidence that eye-tracking can be used to measure the relative perceived beauty of natural images reflecting the attention given to 'attractive' images.

\section{Introduction}

The importance of aesthetic characteristics of a destination is well recognized in tourism literature as natural beauty is one of the key reasons for tourists to visit a place (Kirillova, Fu, Lehto, \& Cai, 2014; Todd, 2009; Yoon \& Uysal, 2005). The aesthetic qualities of a destination affect tourists' experience in that place, their satisfaction, loyalty and revisit intentions (Chi \& Qu, 2008; Lee, Jeon, \& Kim, 2011; O’Leary \& Deegan, 2003; Tan \& Kuo, 2014). Indeed, tourist perceived 
beauty of a destination plays a critical role in destination choice process (Vogt, Fesenmaier, \& MacKay, 1994). For example, UNESCO World Heritage Listed Regions such as the Great Barrier Reef (GBR) attracts millions of tourists to North Queensland because of their aesthetic reputation (Johnston, Smith, \& Dyke, 2013; Packer, Ballantyne, \& Hughes, 2014).

The GBR Marine Park application for listing as a World Heritage Area states that it is a region of 'natural beauty' that 'contains superlative natural phenomena or areas of exceptional natural beauty and aesthetic importance' (Great Barrier Reef Marine Park Authority, 2014, p. 93). This natural beauty extends 'above and below the water' (Great Barrier Reef Marine Park Authority, 2014, p. 280). However, The Great Barrier Reef Outlook Report 2014 (Great Barrier Reef Marine Park Authority, 2014, p. 100) indicates the underwater beauty of the GBR is under threat due to a reduction in coral cover and reduced water clarity.

The [GBR] Region generally continues to be an area of great natural beauty; however, coastal infrastructure, marine debris [especially on beaches], reduced water clarity and declining coral cover, especially in southern and central inshore areas, have reduced underwater aesthetic values.

Given the importance of maintaining the natural beauty of places such as the GBR, it is somewhat surprising that there is no agreed approach to evaluating perceived beauty. Some prior work has made recommendations, but no objective assessment method is as yet available (Context Pty Ltd, 2013). Development of an objective approach to the measurement of perceived beauty would enable aesthetic assessments to be included into destination management and conservation planning, allowing changes in the beauty of the GBR to be monitored (Marshall, Marshall, \& Smith, 2017). This paper reports on research 
conducted to develop an objective method to monitor the perceived underwater scenic beauty of the GBR.

The method is based on the idea of beauty as a subjective mental evaluation of a perceived object (i.e. a visual scene or picture) (Berlyne, 1973; Lothian, 1999). Individual aesthetic evaluations of an object will differ due to variations in expertise or preferences, but an individual's evaluation of an object's beauty is correlated to subconscious visual attention processes and the eye-movements they direct (Calvo \& Lang, 2004; Nummenmaa, Hyönä, \& Calvo, 2006). Such eyemovements can be tracked, and their important characteristics such as fixations and saccades, measured using eye-tracking equipment (Leder, Mitrovic, \& Goller, 2016; Scott, Zhang, Le, \& Moyle, 2017). Therefore, certain characteristics of an individual's eye-movements when exposed to a series of images provide an indicator of the subject's relative aesthetic evaluation of those images.

The aim of this paper then is to provide a method for evaluating the relative beauty of a series of images of the coral, fish and other underwater characteristics of the GBR. The method was tested by examining the relationship between eyetracking measures and respondent beauty scores. Specifically, sixty-six respondents were asked to rank the beauty of 21 underwater photographs on a 10point scale. The averages of these rankings were correlated with visual attention measures of the same images obtained using eye-tracking methods in a laboratory setting (Scott, Green, \& Fairley, 2016). The paper contributes to the literature by demonstrating the potential of using eye-tracking technology in aesthetic research: significant correlations between average perceived beauty rankings and average 
eye-tracking measures were confirmed.

\section{Literature review}

\section{Aesthetic experience and beauty}

The conceptualization of beauty may be grouped into objective and subjective approaches (Lothian, 1999). The first considers that beauty is an objective and intrinsic characteristic of an object. In this view beauty is 'an aspect of the experience of idealisation in which an object(s), sound(s), or concept(s) is believed to possess qualities of formal perfection' (Hagman, 2002, p. 661). Interaction with, or experience of, objects with this property leads to recognition of their intrinsic beauty. Indeed the ability to recognize beauty is an important human capacity, and the 'subjective experience of beauty leads to a sublime and exalted state that is unique, psychologically significant and desirable' (Hagman, 2002, p. 661). The sense of beauty is often found in nature and associated with a feeling of wholeness, pleasure, a lessening of anxiety, awe, joy, excitement, relaxation and contentment (Kirillova \& Lehto, 2016; Lynn, Chen, Scott, \& Benckendorff, 2017; Todd, 2009).

The phrase 'beauty is in the eye of the beholder' reflects an alternative subjective approach to the conceptualization of beauty. This means that an object can have no objective property of beauty and that it is the person's perception and interpretation of the object that determines its perceived beauty. This subjective view considers that recognition of beauty is 'a pleasure which is experienced 
through the perception of an object' (Lothian, 1999, p. 190). This study adopts the subjective approach to beauty treating it as a human reaction that varies across different viewers and cultures (Hekkert \& Leder, 2008). Such human reactions are measurable and such measurements can provide an objective measure of 'beauty'. This second approach is consistent with the empirical aesthetics of Berlyne (1973) whereby neuroscientific evidence is considered to strengthen, complement, and constrain explanation of beauty at the psychological level (Cela-Conde, Agnati, Huston, Mora, \& Nadal, 2011; Leder \& Nadal, 2014). Thus, the perceived beauty of a landscape is derived from perceptual responses of respondents (Kara, 2013; Karmanov, 2009).

Compared to beauty, the more general term of aesthetics deals with the 'experience of objects which provide the consumer with an element of beauty' (Charters, 2006, p. 239). Therefore, objects which are perceived as beautiful are experienced as pleasurable through an aesthetic process. This aesthetic experience of human beauty influences subsequent judgements, favouring the beautiful. (Lindell \& Lindell, 2014). Hence, objects, or images, which are pleasing to the eye, are of considered of higher value in terms of their aesthetic beauty (Haas et al., 2015). In this way, the concept of perceived beauty is similar to attractiveness (Lindell \& Lindell, 2014, p. 768).

Prior research has found that aesthetic appreciation of art relies on the brain's reward processes involved in reward representation, prediction and anticipation, affective self-monitoring, emotions, and the generation of pleasure (Leder \& Nadal, 2014). This suggests that reward (i.e. wanting the aesthetic experience) 
triggers aesthetic preference, judgment, and subsequently decision (Leder, Belke, Oeberst, \& Augustin, 2004; Reimann, Zaichkowsky, Neuhaus, Bender, \& Weber, 2010). Cognitive appraisal describes the process by which individuals evaluate whether an encounter with the environment is relevant to their well-being (Lazarus, 1991). The type and intensity of aesthetic response to an object depend on the degree of expertise of the viewer. In a comparison of experts and nonexperts (measured by facial EMG and several rating scales), experts gave distinctively different evaluations, not only to the artworks but also to a control set of emotional images (Leder \& Nadal, 2014). This suggests that expert evaluations of scenery and images may vary from those of lay people. The aesthetic evaluation processes that allow the identification of an object as having the attribute of beauty are based on sensory (usually visual) perception (Ross, 2016). Human visual perception allows attentional processes a major function in selecting relevant stimuli for detailed examination (Nummenmaa et al., 2006).

\section{Tourism and beauty}

Beauty is recognized as an important characteristic of tourism destinations and experiences (Beza, 2010; Breiby \& Slåtten, 2015; Horng, Chou, Liu, \& Tsai, 2013; Kirillova et al., 2014; Kirillova \& Lehto, 2016; Knudsen, Metro-Roland, \& Rickly, 2015), albeit from a traditionally British perspective (Andrews, 1989).

Beauty is often associated with natural scenery (Beza, 2010), emotional reactions (Breiby \& Slåtten, 2015), and subsequently benefits including restoration (Kaplan, 1995). Breiby (2014, p. 171) found that experts considered that the aesthetics of 
nature-based tourism involved key concepts of 'perception, structure, senses, beauty, and pleasant'. However, as in the literature of consumer behaviour (Patrick \& Peracchio, 2010), psychology (Arnheim, 1966; Leder \& Nadal, 2014) and nature research (Carlson, 2009), the principal perspective on aesthetic appreciation found in the tourism-related literature is objective in nature, that is that the beauty of a scene is connected to the characteristics of a destination rather than the observer's evaluation (Kirillova, 2015; Kirillova et al., 2014; Kirillova \& Lehto, 2016).

Again, despite the importance of sun and sea tourism, the literature of marine aesthetics and coral reefs is restricted (Cracknell, White, Pahl, \& Depledge, 2017; White et al., 2010). Pocock (2002) and Johnston and Smith (2014) have discussed the aesthetic values of the GBR highlighting the significance of beauty for World Heritage listing. Other studies have looked at people's preferences for, affective responses to, and the restorative potential of, different types of public aquaria exhibits (Cracknell et al., 2017). Dinsdale (2009) showed that human visual evaluations provided a consistent judgment of coral reef status regardless of their previous knowledge or exposure to these particular ecosystems. There is evidence that the evaluations of images of the pristine or damaged coral reefs can be in terms of pleasant or ugly. Coral reef photographs are associated with the 'good' end of the evaluation dimension (Dinsdale, 2009).

In summary, the beauty of a photo is considered here a personal judgment based on pleasant emotional reactions to the photo. The perception of beauty causes a reorientation of attention towards the object that is perceived as beautiful. 
Therefore, the study proposes that there will be significant correlations between attention to and perceived beauty/ugliness of images of underwater coral reefs and scenes. The following hypotheses are to be tested:

H1: Viewers will pay more attention (measured by fixation count, fixation duration and total time visit) to beautiful pictures than ugly pictures of natural scenes.

H2: There is a significant relationship between eye-tracking measures (fixation count, fixation duration and total time visit) and perceived beauty of natural scenes.

\section{Methodology}

There have been a number of methods used to study the perceived pleasantness or aesthetic reaction to landscape scenery and underwater images. These include photograph viewing and rating of pleasantness (Cracknell et al., 2017; Locher, Krupinski, Mello-Thoms, \& Nodine, 2007) evaluations of attractiveness and emotion (White et al., 2010), and use of psychophysical approaches to assessment of aesthetic quality of natural environments (Chang, Hammitt, Chen, Machnik, \& $\mathrm{Su}, 2008)$. Existing methods used to determine scenic preference often depend on rating the perceived beauty of an image holistically or in terms of presence or absence of visual elements such as buildings or trees (DEHP, 2017). Photo rating is a standard method with a long tradition in both landscape architecture and environmental psychology and is useful when looking at components of a scene (Van den Berg, Koole, \& Van der Wulp, 2003).

More recently, eye-tracking techniques have been used for the assessment of landscape characteristics (Nordh, 2012). Eye-tracking techniques can measure 
visual attention processes in terms of the number or duration of eye-fixations on images. Eye-tracking has been used to measure preferential attention to emotional pictures (Calvo \& Lang, 2004) and videos (Teixeira, Wedel, \& Pieters, 2012). These studies indicate that an emotional picture, either pleasant or unpleasant, is more likely to be fixated than a neutral picture (Simola, Le Fevre, Torniainen, \& Baccino, 2015). Emotional pictures capture attention during the early stages of picture processing by our brain (Nummenmaa et al., 2006). Similar effects have been observed between facial attractiveness and fixation duration (Leder et al., 2016). Similarly, EEG studies indicate that attention is captured automatically by emotional images (Hajcak, MacNamara, \& Olvet, 2010). A recent meta-analysis shows an attentional bias for positive as compared with neutral stimuli (Pool, Brosch, Delplanque, \& Sander, 2016). Empirical research has noted differences in attention as measured by eye fixations to pleasant and unpleasant scenes (Calvo \& Lang, 2004). Interestingly, eye-tracking studies have noted that expert and lay viewers look at different parts of a landscape scene (Dupont, Antrop, \& Van Eetvelde, 2015). This study uses two methods to evaluate 21 images of underwater reef scenes; eye-tracking provides a measure of attention while selfcompletion questions were used to rate images and obtain an average beauty rating of each picture. This will allow the correlation between these two methods to be established. Each of the variables to be measured is discussed below.

Image rating: There are varieties of different measurement items used to evaluate the perceived beauty of a scene or image. These include ratings of pleasantness (Locher et al., 2007) and beauty (Arriaza, Cañas-Ortega, Cañas-Madueño, \& 
Ruiz-Aviles, 2004). For example, (Beza, 2010) used a bipolar rating scale, based on the semantic differential of 'beautiful' and 'ugly'. The overall ranking of perceived beauty (rather than about aesthetic dimensions of beautiful scenes) is measured by questions about attractiveness or beauty (Cracknell et al., 2017; Tan \& Kuo, 2014; Wang, Zhao, \& Liu, 2016). A 10-point scale is common in aesthetic research (Cracknell et al., 2017; White et al., 2010) which provides comparable and transferable data in comparison with other 5- or 7-point scales (Dawes, 2008). Hence, a self-report item was used in this study evaluating the beauty of each picture (1-Not beautiful at all, 10-Very beautiful).

Attention and beauty: Eye tracking is a useful technique for objective measurement of attention (Scott et al., 2017) by determining when an individual's eye pauses to examine or interpret a component of an advertisement or image (Rayner, Rotello, Stewart, Keir, \& Duffy, 2001). Eye-tracking has been used to measure preference for advertising (Scott et al., 2016), and interest in parts of a landscape image (De Lucio, Mohamadian, Ruiz, Banayas, \& Bernaldez, 1996). The number of discrete fixations (in a given region over the course of scene viewing) is related to the rated informativeness of the region, with regions rated more informative receiving more fixations (Henderson \& Hollingworth, 1999). In the present study, the fixation count, fixation duration and total time visit were used to measure attention, considered here as to the degree of attraction for the observer (i.e. a measure of beauty).

Procedure: The study was conducted in April and May 2017 under the ethical approval GU 2017/ 
537. Respondents provided informed consent before their participation. Tobii T60 Eye Tracker model 2013 equipment was used to collect eye-tracking data. Respondents sat in a chair in an upright position and viewed images on a computer monitor in a quiet laboratory. A convenience sampling method was applied to facilitate data collection. Sixty-six participants were recruited after a calibration process in order to exclude subjects with eyes problems. During the calibration procedure, subjects were asked to look at specific points on the screen, also known as calibration dots while their eye movements were collected and analyzed ('Tobii Pro online guidelines,' 2019). Next, participants were asked to look at images of the GBR. Participants were free to look at each picture on the screen as long as they want during which time their eye fixations were recorded. The order of pictures was randomized to avoid any possible effect related to picture order. After viewing a picture, respondents rated the picture beauty on a 10-point scale (1-Not beautiful at all, 10-Very beautiful).

Analysis: The Tobii eye-tracker provides a record of the direction of the respondent's gaze some 60 times per second and 'maps' this onto a location on the image being viewed. Subsequently, these mapped points were analyzed to determine fixation count and duration data. In the study, the criteria for fixation was $200 \mathrm{~ms}$ which is the standard in eye-tracking research (Jacob \& Karn, 2003; Pan, Zhang, \& Smith, 2011; Wang \& Sparks, 2016). Eye-tracking data including fixation count, fixation duration, and total time visit were estimated by Tobii eyetracking software. The eye-tracking data and image beauty evaluations for each photo were then exported to IBM SPSS version 24 where t-tests and correlation 
analyses were conducted. All pictures used in the eye-tracking experiment, their average beauty scores and heat maps showing participants' attention are provided in the appendix.

\section{Results}

Descriptive statistics were used to analyse the demographic profile of the whole sample of respondents $(n=66)$ (Table 1). A reasonable balance was achieved between male and female respondents. Most subjects were under 35 years old (63 participants) and are students (59 participants).

The research hypotheses were tested through several steps of data analysis. First, the scores for the 21 selected pictures were grouped and their average beauty scores used to identify beautiful (beauty scores $\geq 5$ ) and ugly pictures (beauty scores $<5)$. The results show that 13 pictures were rated as ugly and 8 pictures were considered as beautiful. An independent t-test was conducted to determine whether there is a significant difference in the eye-tracking measures between beautiful and ugly photos. All eye-tracking measures were significantly different between two groups of pictures. Beautiful pictures have higher means for three eye-tracking measures including picture fixation duration, picture fixation count and picture total time visit in comparison with ugly pictures (with beauty rating under 5) (Table 1). This initial result confirms hypothesis 1 that beautiful pictures attract more attention than ugly pictures. 
Table 1. Characteristics of participants in the eye-tracking experiment.

\begin{tabular}{ll}
\hline Characteristics & Number \\
\hline Gender & \\
Male & 31 \\
Female & 35 \\
Age (years) & \\
$18-25$ & 53 \\
$26-35$ & 10 \\
$36-45$ & 3 \\
Profession & \\
Student & 59 \\
Staff & 6 \\
Managers & 1 \\
Others & 0 \\
\hline
\end{tabular}


Table 2. Independent $T$-test of picture groups (beautiful versus ugly).

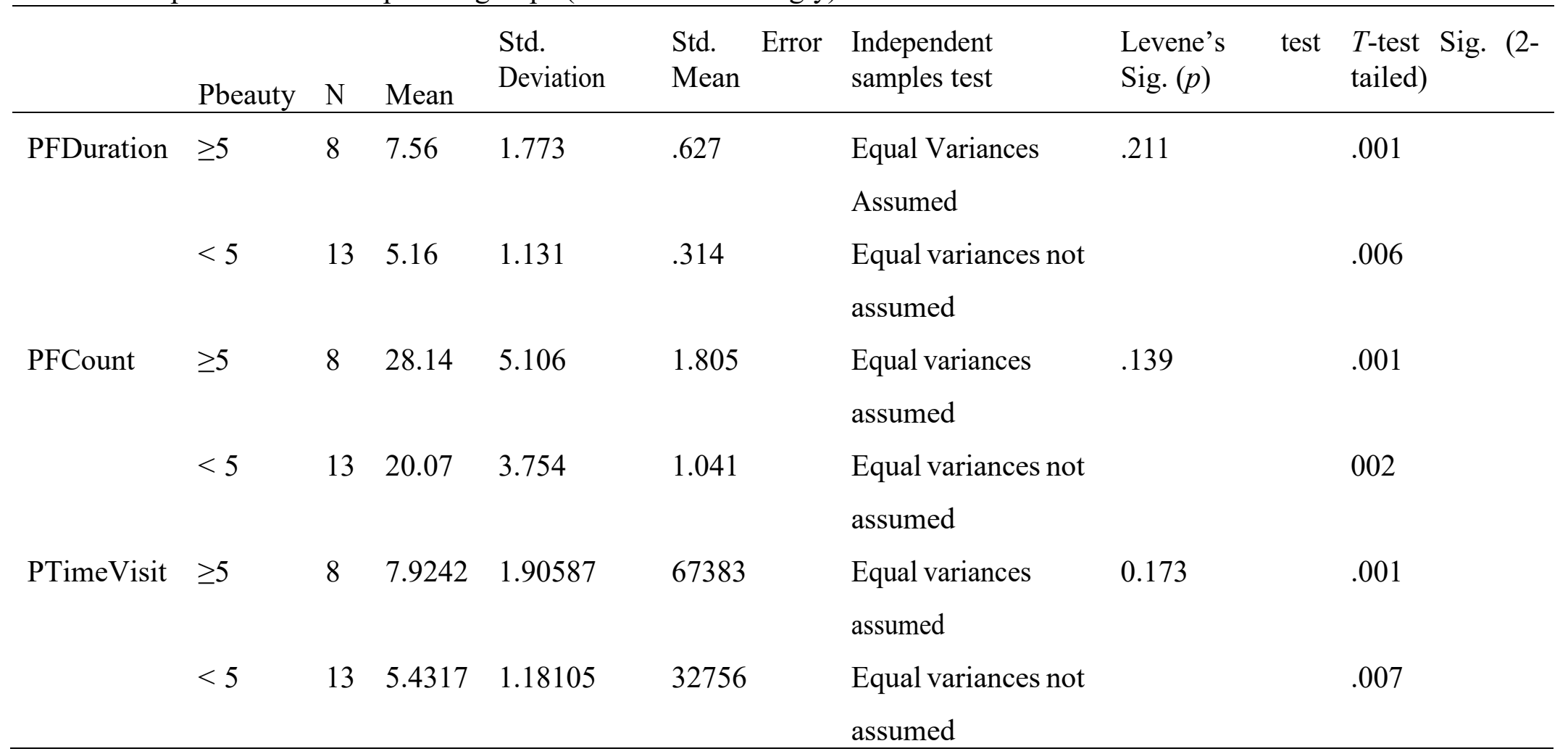

Note: PBeauty: Picture beauty scores rated by participants (from 1 to 10 points). PFDuration: Fixation duration in the picture (i.e. the average length of all fixations during all recordings in the whole picture). A longer fixation means that the object is more engaging in some way. PFCount: Fixation count in the picture (i.e. the average number of fixations in the picture). PTimeVisit: Total time visit for a picture (i.e. the average time participants spent looking at a picture). 
Next, a correlation analysis was conducted to verify whether self-report beauty evaluation and eye-tracking measures are correlated (Table 2). The results indicate that eye-tracking measures (i.e. fixation count, fixation duration, total time visit) were significantly correlated with picture beauty rating. Results of correlation analysis provided a basis for the next step of testing regression models to verify the relationship between eye-tracking measures and perceived beauty.

Three regression models were separately conducted using the three eye-tracking measures that were correlated with picture beauty (Table 4). Because picture fixation duration, picture fixation count and picture total visit time were also correlated (Table 3), they were not included in the same regression model. All three single regression models were found to predict picture beauty. Of the three eye-tracking measures, picture fixation count is the most reliable indicator of picture beauty explaining $45.1 \%$ of variations in picture beauty (Adjusted $R^{2}=0.451, p<0.01$ ). Hence, tourist attention paid to a natural picture as measured by eye-tracking device reflects their beauty evaluation. Based on this, hypothesis 2 is confirmed. 
Table 3. Correlations between averages of variables (all pictures).

\begin{tabular}{llll}
\hline PBeauty & PF duration & PF count & $\begin{array}{l}\text { PTime } \\
\text { visit }\end{array}$ \\
\hline PBeauty 1 & $0.613^{*}$ & $0.692^{* *}$ & $0.603^{* *}$ \\
& 0.003 & 0.001 & 0.004 \\
PFDuration & 1 & $0.968^{* *}$ & $0.999^{* *}$ \\
& & 0.000 & 0.000 \\
PFCount & & 1 & $0.966^{* *}$ \\
& & & 0.000 \\
PTimeVisit & & & 1 \\
\hline
\end{tabular}

*Correlation is significant at the 0.05 level (2-tailed).

$* *$ Correlation is significant at the 0.01 level (2-tailed). 
Table 4. Single regression models of picture beauty using eye-tracking measures.

\begin{tabular}{|c|c|c|c|c|c|}
\hline \multirow{2}{*}{\multicolumn{2}{|c|}{ Model }} & \multicolumn{2}{|c|}{ Model summary } & \multirow[b]{2}{*}{$\begin{array}{l}\text { Unstandardized } \\
\text { coefficients }\end{array}$} & \multirow[b]{2}{*}{$\begin{array}{l}\text { Coefficien } \\
\text { s Sig. }\end{array}$} \\
\hline & & $\begin{array}{l}\begin{array}{l}\text { Adjusted } R \\
\text { square }\end{array} \\
\end{array}$ & $\begin{array}{l}\text { ANOV } \\
\text { A sig. }\end{array}$ & & \\
\hline \multirow[t]{2}{*}{1} & (Constant) & 0.343 & 0.003 & -0.352 & .827 \\
\hline & PFDuration & & & 0.850 & .003 \\
\hline \multirow[t]{2}{*}{2} & (Constant) & 0.451 & 0.001 & -2.131 & 0.228 \\
\hline & PFCount & & & 0.300 & 0.001 \\
\hline \multirow[t]{2}{*}{3} & (Constant) & 0.330 & 0.004 & -0.257 & 0.874 \\
\hline & PTimeVisit & & & 0.794 & 0.004 \\
\hline
\end{tabular}

Dependent variable: picture beauty

\section{Discussion}

This research has tested an innovative eye-tracking method to measure the relative perceived beauty of images taken of underwater scenes from the Great Barrier Reef. In this study, beautiful pictures which are pleasant to the eyes will attract more attention than ugly pictures (H1 confirmed). On average, participants spend about 8 seconds viewing a beautiful picture in comparison for 5.4 seconds per ugly picture. Our research outcome supports for aspects of Leder et al.'s (2004) five- stage model of aesthetic appreciation and aesthetic judgment. The first three stages involve bottom-up perceptual processes to recognize and analyse pictorial features (i.e. perceptual analyses), its profotypicality and familiarity (i.e. implicit memory integration) and its style and content (i.e. explicit classification). Normally, these automatic processing stages could occur rapidly and 
automatically in the first 3 seconds of looking at a picture (Locher et al., 2007). Hence, people are able to make a rapid evaluation of a picture's content and aesthetic appeal at first glance (after the first 3 seconds) (Rasche \& Koch, 2002). The fourth and fifth stages of aesthetic experience involving self-related interpretation and aesthetic appreciation are more deliberate (i.e. top-down) processes. Viewers can decide to stop or spend more time looking at a picture depending on its aesthetic pleasure (Locher et al., 2007). Our research outcome confirms the importance of using beautiful and pleasant images in tourism marketing to capture and retain tourist attention (Wang \& Sparks, 2016). Because tourists are exposed to thousands of visual stimuli per day, audience attention to a tourism marketing message is a key success factor (Scott et al., 2017).

Moreover, it was found that eye-tracking measures (i.e. fixation count, fixation duration and total time visit) can be used as reliable indicators of perceived beauty of natural scenes (H2 confirmed). Aesthetic value is an important criterion of natural attractions like the Great Barrier Reef and its World Heritage listing. To date, there is no systematic and consistent methodology on how to assess the 'natural beauty or aesthetic value' (as articulated as part of Criterion vii in the statements of Outstanding Universal Value) within the World Heritage Convention (Mitchell, Migon, Denyer, \& Leitão, 2013). This study contributes to the development of such a methodology. The eye-tracking method suggests a means for objective measurement of the relative beauty of natural images and potentially for monitoring the aesthetics of environments such as underwater coral reefs. Use of this method may allow the tracking of beauty over time and hence 
contribute to monitoring the sustainability of world heritage areas (de Fauconberg, Berthon, \& Berthon, 2018). Based on our research findings, eye-tracking technology could also be applied by tourism marketers in market research to compare and identify the most beautiful and attractive images of a natural attraction for tourism promotion purpose.

The results of this research provide further evidence of the usefulness of eyetracking methods specifically and of cognitive psychology theory and methods generally in informing tourism research. Previous studies primarily applied retrospective self-reported measures of attention (Dowray, Swartz, Braxton, \& Viera, 2013; Mackison, Wrieden, \& Anderson, 2010; Verbeke \& Ward, 2006) which are likely biased operationalization of identifying true attention (Bialkova \& van Trijp, 2011). Hence, researchers have recently begun to apply eye-tracking methods to study the actual attention of tourists paid to tourism marketing stimuli, for example, images for hotels and airline marketing (Babakhani, Ritchie, \& Dolnicar, 2017; Wang, Tsai, \& Tang, 2018). Eye-tracking can be beneficial in investigating many further topics including evaluation of sponsorship (Breuer \& Rumpf, 2012), advertising effectiveness (Scott et al., 2016) and wayfinding (Xia, Arrowsmith, Jackson, \& Cartwright, 2008). Mobile eye-tracking technology is also available for future research to track individual eye movements at real-life tourism attractions such as a national park or art exhibition.

Moreover, we highly recommend further use of other advanced research technologies such as heart rate, skin conductance, EEG in advancing tourism research (Li, Scott, \& Walters, 2015). These technologies are nowadays available 
at reasonable costs and have great potential to reduce research bias due to memory-based measures. Combining these research tools to examine the nature and relationships between tourist attention (eye-tracking), emotion (heart rate or skin conductance), involvement and information processing (EEG) is very promising in moving the tourist behaviour field forward.

This research is an initial study only and has several limitations. First, only one item was used to measure respondents self-reported beauty ranking, and it may also be useful to use other scales such as visual appeal (Mathwick, Malhotra, \& Rigdon, 2001). Further research is needed to develop this method and compare its results with the expert-based judgment of aesthetic value (Beza, 2010; Schirpke, Timmermann, Tappeiner, \& Tasser, 2016) especially of coral reefs (Goldman, 1990; Johnston \& Smith, 2014). Second, this study is limited in terms of the number of images used ( 21 photos). The method needs retesting using larger numbers of photos - perhaps 60 pictures or more. Third, picture elements were not investigated in this study. However, it was found that photos with brightly coloured coral, multiple fish species, clear water and iconic species such as turtles were found more attractive. Photos rated as less attractive typically showed manmade objects such as discarded cans or bottles or expanses of white coral, less clear water and less fish. Therefore, beauty factors such as the quality of images, including factors such as colour composition, saturation and brightness (Seresinhe, Preis, \& Moat, 2017) and special research methods such as conjoint analysis may be useful to determine the contribution of image elements to aesthetic assessment. 
of other eye-tracking metrics and techniques are available to measure attention such as gaze-entropy (Raptis et al., 2017) and scan-path length (Katsini et al., 2018). Hence, more sophisticated eye-tracking experiments should be set up in future studies. Fifth, only Australian participants were employed for this study. It would be useful to examine respondents from different cultural backgrounds (Asia vs Western) to determine if there are differences in their aesthetic perception. There is some evidence to suggest that there are differences in fixations on areas of interest in an image (Wang \& Sparks, 2016) and variations in eye-movements during scene perception related to the culture of the subject (Chua, Boland, \& Nisbett, 2005).

\section{Acknowledgement}

This study was conducted within a NESP-Tropical Water Quality Hub project (3.2.3) on the 'Monitoring aesthetic value of the Great Barrier Reef by using artificial intelligence to score photos and videos'.

\section{Disclosure statement}

No potential conflict of interest was reported by the authors.

\section{Funding}


This work was supported by National Environment Science Program Tropical Water Quality Hub [grant number NESP- Tropical Water Quality Hub project (3.2.3)]. 


\section{References}

Andrews, M. (1989). The search for the picturesque: Landscape aesthetics and tourism in Britain, 1760-1800. Aldershot: Gower Publishing.

Arnheim, R. (1966). Toward a psychology of art: Collected essays (Vol. 242). Berkeley, CA: University of California Press. Arriaza, M., Cañas-Ortega, J. F., Cañas-Madueño, J. A., \& Ruiz-Aviles, P. (2004). Assessing the visual quality of rural landscapes. Landscape and Urban Planning, 69(1), 115-125. doi:10.1016/j.landurbplan.2003.10.029

Babakhani, N., Ritchie, B. W., \& Dolnicar, S. (2017). Improving carbon offsetting appeals in online airplane ticket purchasing: Testing new messages, and using new test methods. Journal of Sustainable Tourism, 25(7), 955-969.

Berlyne, D. (1973). Aesthetics and psychobiology. New York: Appleton-CenturyCrofts. doi: $10.2307 / 429334$

Beza, B. (2010). The aesthetic value of a mountain landscape: A study of the Mt. Everest Trek. Landscape and Urban Planning, 97(4), 306-317.

Bialkova, S., \& van Trijp, H. C. (2011). An efficient methodology for assessing attention to and effect of nutrition information displayed front-of-pack. Food Quality and Preference, 22(6), 592-601.

Breiby, M. A. (2014). Exploring aesthetic dimensions in a nature-based tourism context. Journal of Vacation Marketing, 20 (2), 163-173. doi:10.1177/1356766713514243

Breiby, M., \& Slåtten, T. (2015). The effects of aesthetic experiential qualities on tourists' positive emotions and loyalty: A case of a nature-based context in Norway. Journal of Quality Assurance in Hospitality \& Tourism, 16(4), 323-346.

Breuer, C., \& Rumpf, C. (2012). The viewer's reception and processing of sponsorship information in sport telecasts. Journal of Sport Management, 26(6), $521-531$. 
Calvo, M., \& Lang, P. (2004). Gaze patterns when looking at emotional pictures: Motivationally biased attention. Motivation and Emotion, 28(3), 221-243.

Carlson, A. (2009). Nature and landscape: An introduction to environmental aesthetics. New York: Columbia University Press. Cela-Conde, C., Agnati, L., Huston, J., Mora, F., \& Nadal, M. (2011). The neural foundations of aesthetic appreciation. Progress in Neurobiology, 94(1), 39-48. doi:10.1016/j.pneurobio.2011.03.003

Chang, C.-Y., Hammitt, W. E., Chen, P.-K., Machnik, L., \& Su, W.-C. (2008). Psychophysiological responses and restorative values of natural environments in Taiwan. Landscape and Urban Planning, 85(2), 79-84.

Charters, S. (2006). Aesthetic products and aesthetic consumption: A review. Consumption, Markets and Culture, 9(3), 235-255.

Chi, C., \& Qu, H. (2008). Examining the structural relationships of destination image, tourist satisfaction and destination loyalty: An integrated approach. Tourism Management, 29(4), 624-636.

Chua, H., Boland, J., \& Nisbett, R. (2005). From the cover: Cultural variation in eye movements during scene perception. Proceedings of the National Academy of Sciences, 102(35), 12629-12633.

Context Pty Ltd. (2013). Defining the aesthetic values of the Great Barrier Reef. Canberra: Minister for Sustainability, Environment, Water, Population and Communities.

Cracknell, D., White, M., Pahl, S., \& Depledge, M. (2017). A preliminary investigation into the restorative potential of public aquaria exhibits: A UK student-based study. Landscape Research, 42(1), 18-32.

Dawes, J. (2008). Do data characteristics change according to the number of scale points used? An experiment using 5- point, 7-point and 10-point scales. International Journal of Market Research, 50(1), 61-104.

de Fauconberg, A., Berthon, P., \& Berthon, P. (2018). Rethinking the marketing 
of world heritage sites: Giving the past a sustainable future. Journal of Public Affairs, 18(2), e1655.

DEHP. (2017). Determining scenic preference in the coastal zone. Brisbane: Department of Environment and Science. Retrieved from https://environment.des.qld.gov.au/coastal/development/pdf/gl-cd-scenicpreference-coastal-zone.pdf

De Lucio, J., Mohamadian, M., Ruiz, J., Banayas, J., \& Bernaldez, F. (1996). Visual landscape exploration as revealed by eye movement tracking. Landscape and Urban Planning, 34(2), 135-142.

Dinsdale, E. (2009). Linking ecological and perceptual assessments for environmental management: A coral reef case study. Ecology and Society, 14(2), $1-17$.

Dowray, S., Swartz, J. J., Braxton, D., \& Viera, A. J. (2013). Potential effect of physical activity based menu labels on the calorie content of selected fast food meals. Appetite, 62, 173-181.

Dupont, L., Antrop, M., \& Van Eetvelde, V. (2015). Does landscape related expertise influence the visual perception of landscape photographs? Implications for participatory landscape planning and management. Landscape and Urban Planning, 141, 68-77.

Goldman, A. (1990). Aesthetic qualities and aesthetic value. The Journal of Philosophy, 87(1), 23-37. Great Barrier Reef Marine Park Authority. (2014). Great Barrier Reef outlook report 2014. Townsville: GBRMPA.

Haas, A., Guibert, M., Foerschner, A., Co, T., Calhoun, S., George, E., ... Rohwer, F. (2015). Can we measure beauty?

Computational evaluation of coral reef aesthetics. PeerJ, 3, e1390. doi:10.7717/peerj.1390 Hagman, G. (2002). The sense of beauty. The International Journal of Psychoanalysis, 83(3), 661-674.

Hajcak, G., MacNamara, A., \& Olvet, D. (2010). Event-related potentials, 
emotion, and emotion regulation: An integrative review. Developmental Neuropsychology, 35(2), 129-155.

Hekkert, P., \& Leder, H. (2008). Product aesthetics. In H. N. J. Schifferstein \& P. Hekkert (Eds.), Product experience (pp. 259-285). Amsterdam: Elsevier.

Henderson, J. M., \& Hollingworth, A. (1999). High-level scene perception. Annual Review of Psychology, 50(1), 243-271. Horng, J.-S., Chou, S.-F., Liu, C.H., \& Tsai, C.-Y. (2013). Creativity, aesthetics and eco-friendliness: A physical dining environment design synthetic assessment model of innovative restaurants. Tourism Management, 36, 15-25.

Jacob, R., \& Karn, K. (2003). Eye tracking in human-computer interaction and usability research: Ready to deliver the promises. In R. Radach, J. Hyönä, \& H. Deubel (Eds.), The mind's eye: Cognitive and applied aspects of eye movement research (pp. 573-605). Amsterdam: Elsevier.

Johnston, C., \& Smith, A. (2014). Beautiful one day: Assessing the world heritage aesthetic values of the Great Barrier Reef. Historic Environment, 26(2), 54-71.

Johnston, C., Smith, A., \& Dyke, J. (2013). Defining the aesthetic values of the Great Barrier Reef. Retrieved from http://hdl. handle.net/11017/2855

Kaplan, S. (1995). The restorative benefits of nature: Toward an integrative framework. Journal of Environmental Psychology, 15(3), 169-182.

Kara, B. (2013). Landscape design and cognitive psychology. Procedia - Social and Behavioral Sciences, 82, 288-291. Karmanov, D. (2009). Feeling the landscape: Six psychological studies into landscape experience (Unpublished doctoral dissertation). Wageningen University, Wageningen.

Katsini, C., Fidas, C., Raptis, G., Belk, M., Samaras, G., \& Avouris, N. (2018). Influences of human cognition and visual behavior on password strength during picture password composition. Paper presented at the proceedings of the 2018 $\mathrm{CHI}$ conference on human factors in computing systems, Montreal, Canada.

Kirillova, K. (2015). Destination aesthetics and aesthetic distance in tourism 
experience. Journal of Travel and Tourism Marketing, 32(8), 1051-1068. doi:10.1080/10548408.2014.958608

Kirillova, K., Fu, X., Lehto, X., \& Cai, L. (2014). What makes a destination beautiful? Dimensions of tourist aesthetic judgment. Tourism Management, 42, 282-293.

Kirillova, K., \& Lehto, X. (2016). Aesthetic and restorative qualities of vacation destinations: How are they related? Tourism Analysis, 21(5), 513-527.

Knudsen, D., Metro-Roland, M., \& Rickly, J. (2015). Tourism, aesthetics, and touristic judgment. Tourism Review International, 19(4), 179-191. Lazarus, R. (1991). Emotion and adaptation. New York: Oxford University Press.

Leder, H., Belke, B., Oeberst, A., \& Augustin, D. (2004). A model of aesthetic appreciation and aesthetic judgments. British Journal of Psychology, 95(4), 489508.

Leder, H., Mitrovic, A., \& Goller, J. (2016). How beauty determines gaze! Facial attractiveness and gaze duration in images of real world scenes. $i$-Perception, 7(4), 2041669516664355

Leder, H., \& Nadal, M. (2014). Ten years of a model of aesthetic appreciation and aesthetic judgments: The aesthetic episode-developments and challenges in empirical aesthetics. British Journal of Psychology, 105(4), 443-464.

Lee, S., Jeon, S., \& Kim, D. (2011). The impact of tour quality and tourist satisfaction on tourist loyalty: The case of Chinese tourists in Korea. Tourism Management, 32(5), 1115-1124.

Li, S., Scott, N., \& Walters, G. (2015). Current and potential methods for measuring emotion in tourism experiences: A review. Current Issues in Tourism, $18(9), 805-827$.

Lindell, A., \& Lindell, K. (2014). Beauty captures the attention of the beholder. Journal of Cognitive Psychology, 26(7), 768- 780. doi:10.1080/20445911.2014.963111 
Locher, P., Krupinski, E., Mello-Thoms, C., \& Nodine, C. (2007). Visual interest in pictorial art during an aesthetic experience. Spatial Vision, 21(1), 55-77.

Lothian, A. (1999). Landscape and the philosophy of aesthetics: Is landscape quality inherent in the landscape or in the eye of the beholder? Landscape and Urban Planning, 44(4), 177-198.

Lynn, I., Chen, L., Scott, N., \& Benckendorff, P. (2017). Mindful tourist experiences: A Buddhist perspective. Annals of Tourism Research, 64, 1-12.

Mackison, D., Wrieden, W., \& Anderson, A. (2010). Validity and reliability testing of a short questionnaire developed to assess consumers' use, understanding and perception of food labels. European Journal of Clinical Nutrition, 64(2), 210 217.

Marshall, N., Marshall, P., \& Smith, A. (2017). Managing for aesthetic values in the Great Barrier Reef: Identifying indicators and linking Reef aesthetics with Reef health. Cairns: Reef and Rainforest Research Centre Limited.

Mathwick, C., Malhotra, N., \& Rigdon, E. (2001). Experiential value: Conceptualization, measurement and application in the catalog and Internet shopping environment. Journal of Retailing, 77, 39-56.

Mitchell, N., Migon, P., Denyer, S., \& Leitão, L. (2013). Study on the application of criterion (vii): Considering superlative natural phenomena and exceptional natural beauty within the world heritage convention. Gland: International Union for Conservation of Nature.

Nordh, H. (2012). Quantitative methods of measuring restorative components in urban public parks. Journal of Landscape Architecture, 7(1), 46-53.

Nummenmaa, L., Hyönä, J., \& Calvo, M. G. (2006). Eye movement assessment of selective attentional capture by emotional pictures. Emotion, 6(2), 257-268.

O’Leary, S., \& Deegan, J. (2003). People, pace, place: Qualitative and quantitative images of Ireland as a tourism destination in France. Journal of Vacation Marketing, 9(3), 213-226. 
Packer, J., Ballantyne, R., \& Hughes, K. (2014). Chinese and Australian tourists' attitudes to nature, animals and environmental issues: Implications for the design of nature-based tourism experiences. Tourism Management, 44, 101-107. doi:10.1016/j.tourman.2014.02.013

Pan, B., Zhang, L., \& Smith, K. (2011). A mixed-method study of user behavior and usability on an online travel agency. Information Technology \& Tourism, 13(4), 353-364.

Patrick, V. M., \& Peracchio, L. A. (2010). "Curating" the JCP special issue on aesthetics in consumer psychology: An introduction to the aesthetics issue. Journal of Consumer Psychology, 20(4), 393-397.

Pocock, C. (2002). Sense matters: Aesthetic values of the Great Barrier Reef. International Journal of Heritage Studies, 8(4), 365-381.

Pool, E., Brosch, T., Delplanque, S., \& Sander, D. (2016). Attentional bias for positive emotional stimuli: A meta-analytic investigation. Psychological Bulletin, 142(1), 79-106.

Raptis, G., Katsini, C., Belk, M., Fidas, C., Samaras, G., \& Avouris, N. (2017). Using eye gaze data and visual activities to infer human cognitive styles: Method and feasibility studies. Paper presented at the proceedings of the 25th conference on user modeling, adaptation and personalization, Bratislava, Slovakia.

Rasche, C., \& Koch, C. (2002). Recognizing the gist of a visual scene: Possible perceptual and neural mechanisms. Neurocomputing, 44, 979-984.

Rayner, K., Rotello, C. M., Stewart, A. J., Keir, J., \& Duffy, S. A. (2001). Integrating text and pictorial information: Eye movements when looking at print advertisements. Journal of Experimental Psychology: Applied, 7(3), 219-226.

Reimann, M., Zaichkowsky, J., Neuhaus, C., Bender, T., \& Weber, B. (2010). Aesthetic package design: A behavioral, neural, and psychological investigation. Journal of Consumer Psychology, 20(4), 431-441. doi:10.1016/j.jcps.2010.06.009 Ross, M. (2016). The aesthetic impulse. Oxford: Elsevier. 
Schirpke, U., Timmermann, F., Tappeiner, U., \& Tasser, E. (2016). Cultural ecosystem services of mountain regions: Modelling the aesthetic value. Ecological Indicators, 69, 78-90.

Scott, N., Green, C., \& Fairley, S. (2016). Investigation of the use of eye tracking to examine tourism advertising effectiveness. Current Issues in Tourism, 19(7), 634-642.

Scott, N., Zhang, R., Le, D., \& Moyle, B. (2017). A review of eye-tracking research in tourism. Current Issues in Tourism, 1-18. doi:10.1080/13683500.2017.1367367

Seresinhe, C. I., Preis, T., \& Moat, H. S. (2017). Using deep learning to quantify the beauty of outdoor places. Royal Society Open Science, 4(7), 170170.

Simola, J., Le Fevre, K., Torniainen, J., \& Baccino, T. (2015). Affective processing in natural scene viewing: Valence and arousal interactions in eyefixation-related potentials. Neurolmage, 106, 21-33. doi:10.1016/j.neuroimage.2014.11.030

Tan, W.-K., \& Kuo, C.-Y. (2014). The effect of aesthetic-image value of travel expert blogs on the intention to travel: An exploratory study. Current Issues in Tourism, 17(8), 657-665. doi:10.1080/13683500.2013.840270

Teixeira, T., Wedel, M., \& Pieters, R. (2012). Emotion-induced engagement in internet video advertisements. Journal of Marketing Research, 49(2), 144-159.

Tobii Pro online guidelines. (2019). Retrieved from https://www.tobiipro.com/learn-and-support/learn/eye-tracking- essentials/whathappens-during-the-eye-tracker-calibration/

Todd, C. (2009). Nature, beauty and tourism. In J. Tribe (Ed.), Philosophical issues in tourism (pp. 154-170). Bristol: Channel View Publishing.

Van den Berg, A. E., Koole, S. L., \& Van der Wulp, N. Y. (2003). Environmental preference and restoration: (How) are they related? Journal of Environmental Psychology, 23(2), 135-146. 
Verbeke, W., \& Ward, R. W. (2006). Consumer interest in information cues denoting quality, traceability and origin: An application of ordered probit models to beef labels. Food Quality and Preference, 17(6), 453-467.

Vogt, C., Fesenmaier, D., \& MacKay, K. (1994). Functional and aesthetic information needs underlying the pleasure travel experience. Journal of Travel \& Tourism Marketing, 2(2-3), 133-146. doi:10.1300/J073v02n02_09

Wang, Y., \& Sparks, B. (2016). An eye-tracking study of tourism photo stimuli: Image characteristics and ethnicity. Journal of Travel Research, 55(5), 588-602.

Wang, T.-C., Tsai, C.-L., \& Tang, T.-W. (2018). Restorative quality in tourist hotel marketing pictures: Natural and built characteristics. Current Issues in Tourism, 22(14), 1679-1685.

Wang, R., Zhao, J., \& Liu, Z. (2016). Consensus in visual preferences: The effects of aesthetic quality and landscape types. Urban Forestry \& Urban Greening, 20, 210-217. doi:10.1016/j.ufug.2016.09.005

White, M., Smith, A., Humphryes, K., Pahl, S., Snelling, D., \& Depledge, M. (2010). Blue space: The importance of water for preference, affect, and restorativeness ratings of natural and built scenes. Journal of Environmental Psychology, 30(4), 482-493. doi:10.1016/j.jenvp.2010.04.004

Xia, J. C., Arrowsmith, C., Jackson, M., \& Cartwright, W. (2008). The wayfinding process relationships between decisionmaking and landmark utility. Tourism Management, 29(3), 445-457.

Yoon, Y., \& Uysal, M. (2005). An examination of the effects of motivation and satisfaction on destination loyalty: A structural model. Tourism Management, 26(1), 45-56. doi:10.1016/j.tourman.2003.08.016 